\title{
Two more bird's nest fungi from cold desert of Ladakh, India
}

\section{Yangdol R, Kumar S and Sharma YP}

Department of Botany, University of Jammu, Jammu 180 006, Jammu and Kashmir, India

Yangdol R, Kumar S, Sharma YP 2018 - Two more bird's nest fungi from cold desert of Ladakh, India. Studies in Fungi 3(1), 79-83, Doi 10.5943/sif/3/1/10

\begin{abstract}
Two taxa of Agaricaceae viz., Cyathus colensoi and Cyathus renweii collected from Leh district of Ladakh were described and illustrated. Of these, $C$. renweii is a new report to India and C. colensoi is being reported for the first time from Jammu and Kashmir.
\end{abstract}

Key words - Agaricaceae - Ladakh - New records - Taxonomy

\section{Introduction}

The genus Cyathus belonging to the family Agaricaceae of class Agaricomycetes, is the most common bird's nest fungus characterized by three layered peridium and permanent complex funiculi. Currently, the genus has 45 species distributed worldwide (Kirk et al. 2008) out of which 14 species are reported from India (Brodie 1974, Thind et al. 1984, Thind 2005, Das \& Zhao, 2012, 2013). However, there is only one record of this genus from Jammu and Kashmir. The present study describes two taxa of bird's nest fungi, Cyathus colensoi and Cyathus renweii collected from various locations of Leh district of Ladakh. Cyathus renweii is recorded for the first time from India while $C$. colensoi is reported for the first time from Jammu and Kashmir. These species are additions to earlier studied Cyathus olla (Dorjey et al. 2013).

\section{Materials \& Methods}

Field records were made for habitats, substrates, shape, colour and dimensions of fruit body and the photographs of fresh basidiomes were taken in their natural habitat. Microscopic characters were observed on dried material using hand cut sections after reviving a part of the dried specimen in 3\% KOH solution, and stained with $1 \%$ Congo red and Melzer's reagent. Twenty basidiospores were measured and $\mathrm{Q}$ values were obtained by mean length divided by mean width ratio of basidiospores. Line drawings of microscopic details were drawn with the aid of Camera lucida fitted on Olympus CH 20i binocular microscope. Specimens cited have been deposited at the Herbarium of Botany Department (HBJU), University of Jammu, Jammu and Kashmir. Faces of fungi number of these species are also provided (Jayasiri et al. 2015).

\section{Results \& Discussion}

Cyathus colensoi Berk., in Hooker, Bot. Antarct. Voy. Erebus Terror 1839-1843, II, Fl. Nov. Zeal.: 192 (1855)

Figs $1 \mathrm{a}, \mathrm{b} \& 2$

Facesoffungi number: FoF03836

Synonymy: Cyathodes colensoi (Berk.) Kuntze, Revis, gen. Pl. (Leipzig) 2: 851 (1891) 
Peridium: 6-7 $\mathrm{mm}$ high, 5-6 $\mathrm{mm}$ wide at mouth, campanulate, outer surface pallid gray to grayish brown, finely tomentose but glabrous in age, inner surface smooth, pale gray to lightbrown, margin thick, entire; Peridioles: oval to lenticular, gray to blackish, 1.5-2.0 mm diam., attached to the base of peridium by funicular cord, tunica thin; cortex thick, single layered; Basidiospores: 5.6-8.0 × 4.8-8.0 $\mu \mathrm{m}, \mathrm{L}=6.8 \pm 0.93 \mu \mathrm{m}, \mathrm{W}=6.3 \pm 1.07 \mu \mathrm{m}, \mathrm{Q}=0.9-1.0$, subovoid to ellipsoid, hyaline, thick walled, smooth, inamyloid; Basidia: not observed; Exoperidial hyphae: 2.4-4.8 $\mu \mathrm{m}$ diam., hyaline to olive green, thick walled; Endoperidial hyphae: 2.4-6.4 $\mu \mathrm{m}$ diam.,, hyaline, septate, branched, clamp connections present; Funiculus hyphae: 1.6-3.2 $\mu \mathrm{m}$ diam., hyaline, bulbous septate, branched.

Edibility - Not edible in the study area

Collections examined - Jammu and Kashmir, Leh, Phey village, humicolous, gregarious, Rigzin Yangdol and Y. P. Sharma, HBJU-476, $3^{\text {rd }}$ August, 2014.

Distribution - On dead twigs and soil, West Bengal (Sharma 2016).

Remarks - The above examined collection has been identified as Cyathus colensoi. Its macroscopic and microscopic characters are in conformity with those given for this species by Sharma (2016) except for some variation in basidiospore size. Sharma (2016) documented the spore size range from 8.5-11.5 $\times$ 7.0-8.5 $\mu \mathrm{m}$ as compared to 5.6-8.0 $\times 4.8-8.0 \mu \mathrm{m}$ in our collection. Cyathus microsporus is a related species but differs in having smaller basidiospores and peridioles.
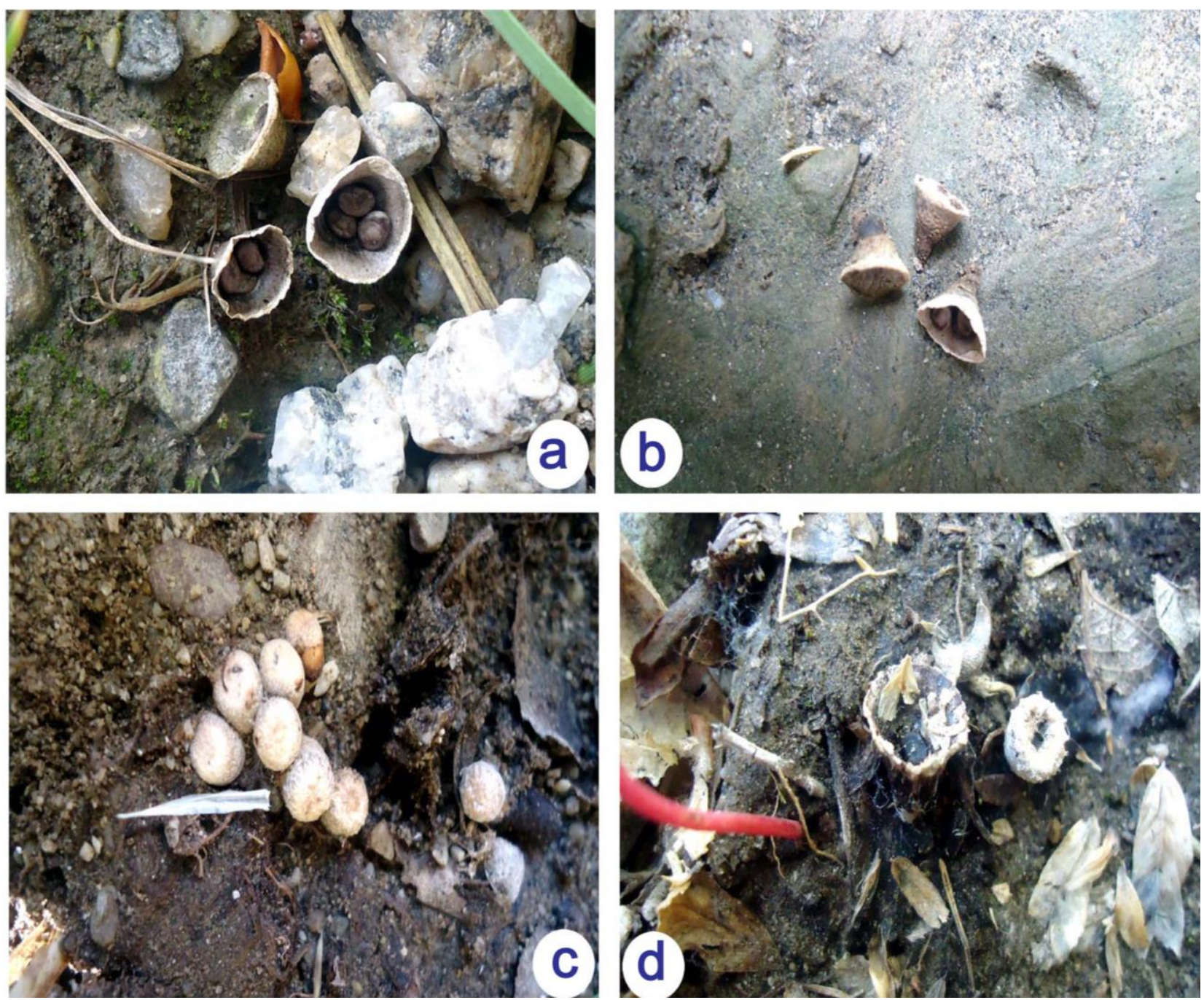

Fig. 1 - a, b Basidiocarps of Cyathus colensoi in natural habitat. c Young fruiting bodies of Cyathus renweii showing gregarious habit. d Young and mature fruiting bodies of Cyathus renweii in natural habitat. 
Cyathus renweii T.X. Zhou \& R.L. Zhao, in Zhou, Zhao, Zhao \& Chen, Fungal Diversity 17: 245 (2004)

Facesoffungi number: FoF03294

Figs $1 \mathrm{c}, \mathrm{d} \& 3$

Peridium: obconic or vase shaped, 6-11 mm high, 5-8 mm wide at mouth, outer surface of peridium brownish, weakly plicate, covered with yellowish to yellowish-cream hairs and narrow tufts, becoming glabrous in age, inner surface silvery gray, strongly plicate only near the mouth; Peridioles: 8-14 in number, round, dark grayish, 1.5-2.0 $\mathrm{mm}$ in diameter and attached at the side of peridium by a funicular cord, cortex single; tunica brown, thick; Basidiospores: 15.2-33.6 $\times 10.4-$ $23.2 \mu \mathrm{m}, \mathrm{L}=24.4 \pm 3.16 \mu \mathrm{m}, \mathrm{W}=16.8 \pm 4.01 \mu \mathrm{m}, \mathrm{Q}=1.44-1.46$, broadly ellipsoidal, ovoid (few), hyaline, double walled, inamyloid; Basidia: not observed; Exoperidial hyphae: 1.6-2.4 $\mu \mathrm{m}$ diam., hyaline, thick walled; Endoperidial hyphae: 2.4-8.0 $\mu \mathrm{m}$ diam., hyaline, thick walled, septate, branched, clamp connections present; Funiculus hyphae: 1.6-2.4 $\mu \mathrm{m}$ diam., hyaline, bulbous septate.

Collections examined - Jammu and Kashmir, Leh, Basgo village, humicolous, scattered, Rigzin Yangdol and Y. P. Sharma, HBJU-478, 24 ${ }^{\text {th }}$ August, 2013.

Distribution - Earlier reported from China (Zhou et al. 2004).

Remarks - The macro- and microscopic characters of the present collection corroborates well with the taxonomic description given by Zhou et al. (2004). It is a new report for India.
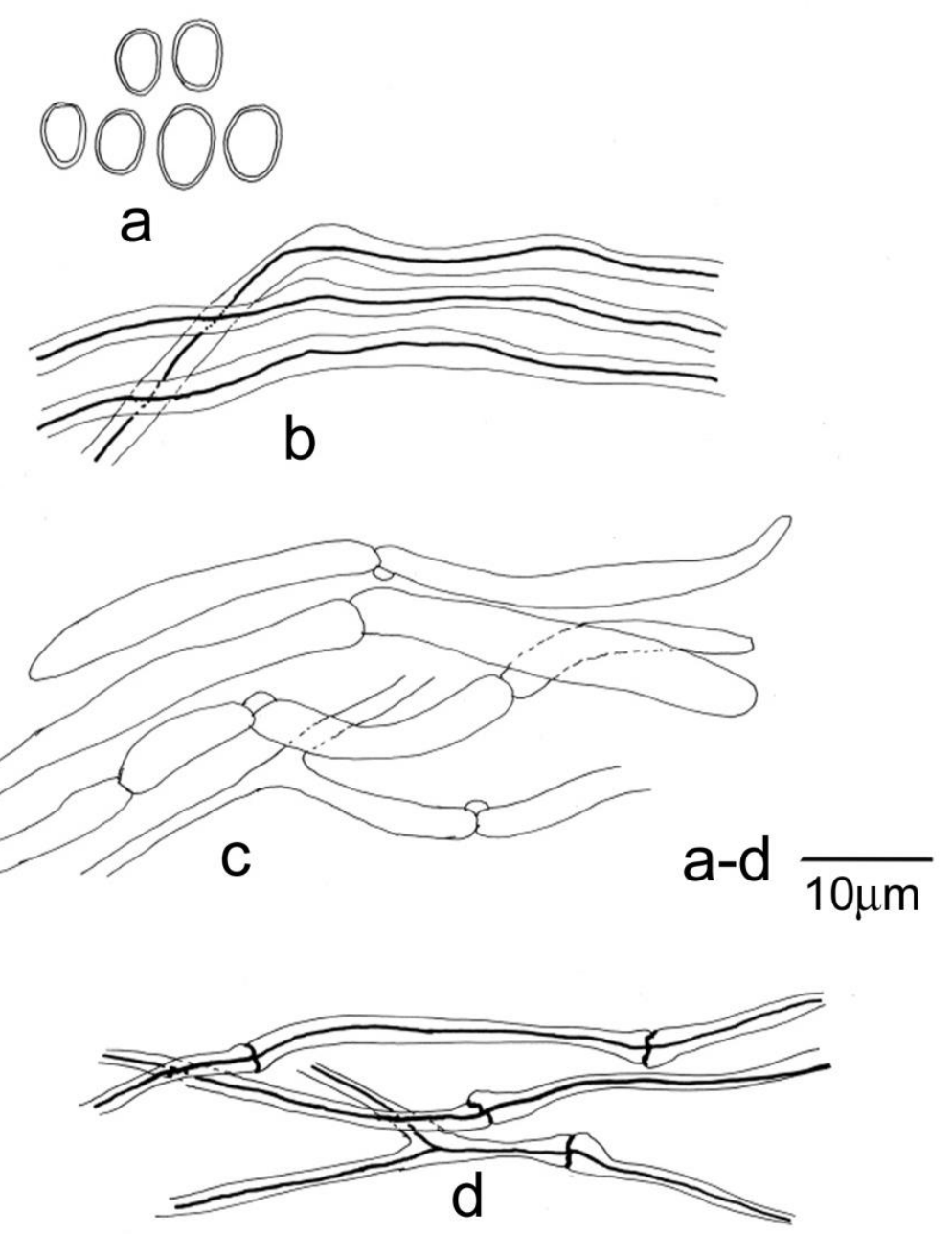

Fig. 2 - Cyathus colensoi. a Basidiospores. b Exoperidial hyphae. c Endoperidial hyphae. d Funiculus hyphae. 

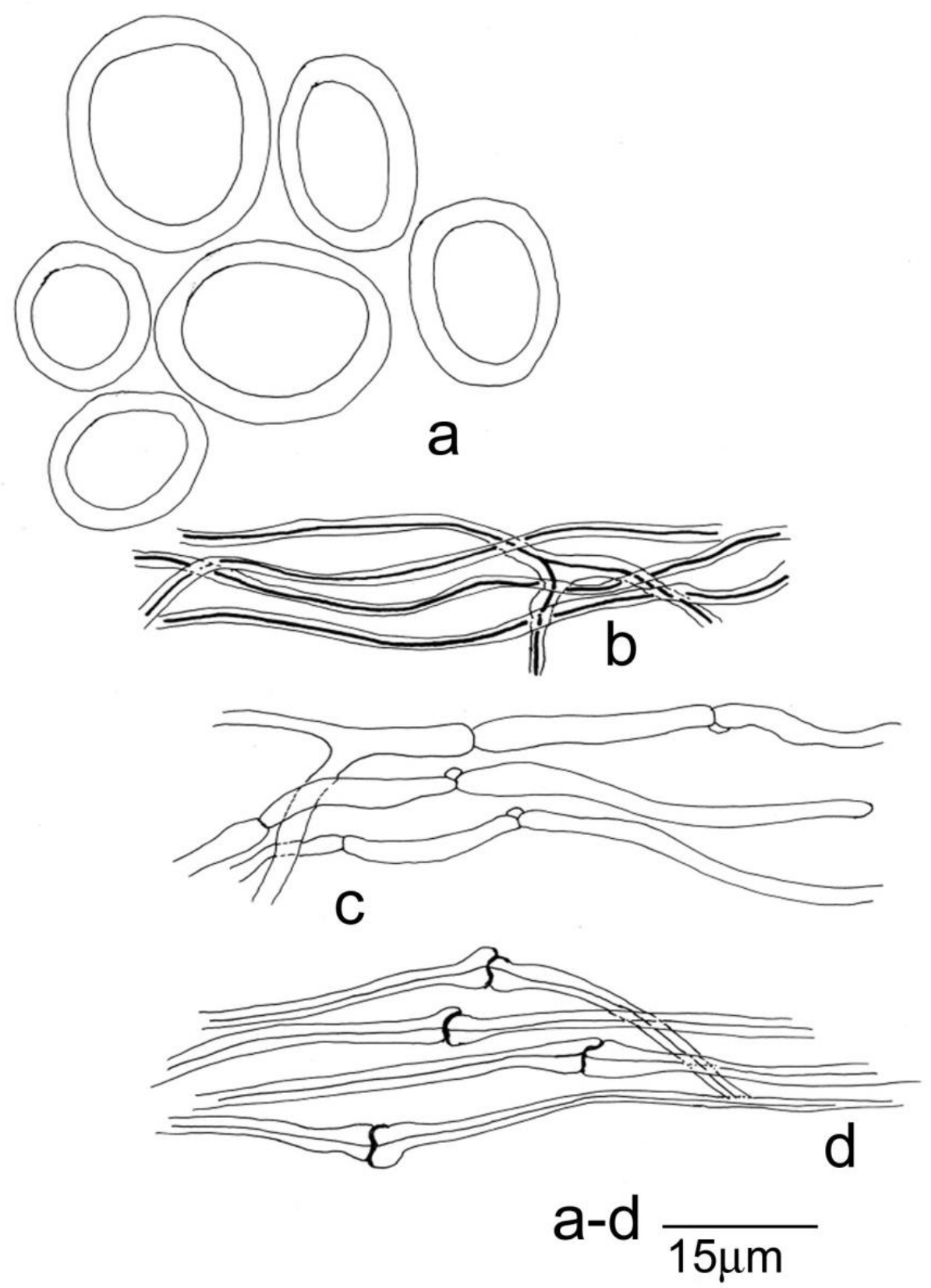

Fig. 3 - Cyathus renweii. a Basidiospores. b Exoperidial hyphae. c Endoperidial hyphae. d Funiculus hyphae.

\section{Acknowledgements}

Authors wish to acknowledge Head, Department of Botany (UGC-SAP DRS II), University of Jammu, Jammu \& Kashmir for providing laboratory facilities. The first author thankfully acknowledges the financial assistance received from UGC (RGNF-ST) in the form of Senior Research Fellow.

\section{References}

Brodie HJ. 1974 - A new plicate from India. Canadian Journal of Botany 52: 247 -249.

Das K, Zhao R. 2012 - Bird's nest fungi in India: A new record from Sikkim. Biodiversity and 
Taxonomy 61-68.

Das K, Zhao R. 2013 - Nidularia shingbaensis sp. nov., a new bird's nest fungus from India. Mycotaxon 125: 53-58.

Dorjey K, Kumar S, Sharma YP. 2013 - Cyathus olla from the cold desert of Ladakh. Mycosphere 4, 256-259.

Jayasiri SC, Hyde KD, Ariyawansa HA, Bhat J et al. 2015 - The faces of fungi database: fungal names linked with morphology, phylogeny and human impacts. Fungal Diversity 74, 3-18.

Kirk P, Cannon PF, Minter DW, Stalpers JA. 2008 - Ainsworth \& Bisby's Dictionary of the Fungi. (10th edition). CAB International, Wallingford, UK, pp 771.

Sharma BM. 2016 - Genus Cyathus Haller ex Pers. (Agaricomycetes) from Eastern Himalaya. Kavaka 47: 20-26.

Thind KS, Thind IPS, Sharma BM. 1984 - The Gasteromycetes of the Himalayas-III. Kavaka $12: 53-57$.

Thind IPS. 2005 - Distribution of gasteromyceteous fungi in North Western Himalayas. In: Fungi Diversity and Conservation in India (eds. Dargan JS, Atri NS, Dhingra GS), Bishen Singh Mahendra Pal Singh, Dehradun, India pp 183-191.

Zhou TX, Zhao LZ, Zhao RL, Chen YH. 2004 - Bird's nest fungi from China. Fungal Diversity 17, 243-251. 